\title{
The finite element analysis of buckling of laminated rectangular reinforced concrete plates with circular hole
}

\author{
Muhammed D.TEKIN",M.Fatih ALTAN**
}

"Professor of civil engineering department, C.B.U.,Manisa,Turkey.

"Research Asistant of civil engineering department, C.B.U., Manisa, Turkey.

\begin{abstract}
In this investigation an approach buckling analysis for simply supported rectangular reinforced concrete plates under uniaxial compression are developed.The objective of this investigation is to compare buckling load of the reinforced plate with circular hole and without hole A laminated composite plate is considered. The finite element models for with central circular hole and without hole are designed. The composite materials and composite laminates materials approach are discussed. The solution of the problem by computer program coded in FORTRAN is explained and numerical example is given.
\end{abstract}

\section{Introduction}

The buckling behaviour of thin plates with a hole and made of composite materials are research topics of great practical importance. For example, composite plate - like subcomponents with holes are being considered for use in many types of structural analysis of building due to various reasons.

The need for a hole in a subcomponent is typically required by practical concerns. For example, windows, air conditioned hole, etc. In some applications, these structural elements are required to resist buckling. Thus an understanding of their buckling behaviour is needed for their design.

Plate - like subcomponents come in many forms such as a rectangular plate with a circular hole. The present study focuses on rectangular plates with a single hole. Developing a through understanding of the behaviour of this subcomponent is a fundamental step toward understanding the behaviour of complex structures with holes such as building structures. Knowledge of the basic response of the subcomponent provides information useful for the preliminary design of complex structures. In addition, this basic knowledge provides valuable insight into modelling complex structures with general purpose finite element codes. Furthermore, knowledge of the subcomponent response is very useful in identifying erroneous results that may occur because of improper finite element modelling.

The present study is to describe the results of research that has been conducted on the buckling behaviour of rectangular composite plates with holes.

\section{Problem description and terminology}

It is necessary to establish some convenient parameters and terminology for describing the plate geometry,loading and boundary conditions and material composition. 
A rectangular plate with a centrally located circular hole is shown in figure 1 . The plate has length $A$ and width $B$. $d$ is the diameter of the hole.Laminate notation is shown in figure 2. $E_{c}$ and $E_{s}$ are modulus of elasticity concrete and steel.

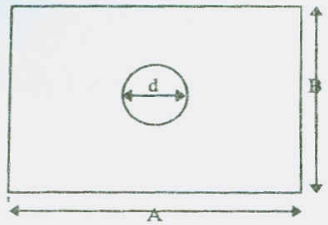

Fig.1. Geometry and dimensions of a plate with a centrally located circular hole.

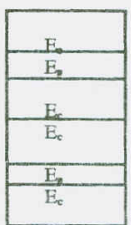

number of laminae Fig. 2. Laminate notation of a plate

\section{Loading conditions}

The loading conditions discussed herein are uniaxial compression loads. For a plate with a hole, there are different ways of applying these loads that generally correspond to different deformation states. These deformation states are associated with the application of displacement or stress boundary conditions to introduce the loads.

The compression loads are applied to a plate by either uniformly displacing or uniformly stressing two opposite exterior plate edge as illustrated in figure.3.

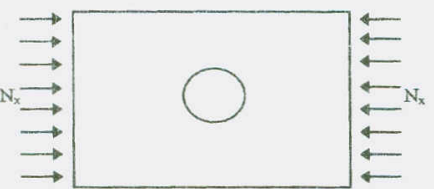

Fig.3. Prebuckling deformation shapes for compression loaded rectangular plates with a central circular hole.

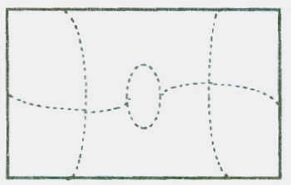

Fig.4. A possible buckling deformation shape.

The compression displacement loadings are particularly important because they are representative of the load transmission that occurs between a plate - like subcomponent and an adjacent support structure that has a much higher relative in plane stiffness. When a plate does not have a hole, the distinction between displacement and stress loadings is unnecessary.

\section{Boundary conditions}

Plates that are simply supported on all edges are referred to herein concisely as simply supported respectively. In all cases considered herein the hole boundary is a free edge. The classical buckling problem for a laminated composite plate requires satisfying the governing differiantial equations derived and the boundary conditions. The deflection and the bending moment along the boundary are zero.

$$
w=0, \quad \frac{\partial^{2} w}{\partial x^{2}}+v \frac{\partial^{2} w}{\partial y^{2}}=0 \quad \text { at } x=0 \text { and } x=L
$$




\section{Material composition}

The materials are concrete and steel. The engineering constants are $\mathrm{E}_{\mathrm{cj}}=3250 \sqrt{\mathrm{f}_{\mathrm{ekj}}}+14000 \mathrm{~N} / \mathrm{mm}^{2}$

$\mathrm{E}_{\mathrm{s}}=2 \times 10^{5} \mathrm{~N} / \mathrm{mm}^{2}$

$v_{c}=0.2$ for concrete.

$\nu_{s}=0.3$ for steel.

where $v$ is poisson's ratio, $\mathbf{E}_{\mathrm{s}}$ is modulus of elasticity for steel, $\mathbf{E}_{\mathrm{cj}}$ is modulus of elasticity for concrete.

\section{Mathematical formulation}

The governing equation of the general plate

$\frac{\partial^{4} w}{\partial x^{4}}+2 \frac{\partial^{4} w}{\partial x^{2} \partial y^{2}}+\frac{\partial^{4} w}{\partial y^{4}}=\frac{1}{D}\left(q+N_{x} \frac{\partial^{2} w}{\partial x^{2}}+N_{y} \frac{\partial^{2} w}{\partial y^{2}}+2 N_{x y} \frac{\partial^{2} w}{\partial x \partial y}\right)$

In this problem, $\mathrm{N}_{\mathrm{y}}, \mathrm{N}_{\mathrm{xy}}$ are zero and $\mathrm{N}_{\mathrm{x}}$ is negative due to compression.

$$
\begin{aligned}
& \frac{\partial^{4} w}{\partial x^{4}}+2 \frac{\partial^{4} w}{\partial x^{2} \partial y^{2}}+\frac{\partial^{4} w}{\partial y^{4}}=\frac{1}{D}\left(-N_{x} \frac{\partial^{2} w}{\partial x^{2}}\right) \\
& {[D]=\left[\begin{array}{ccc}
D & \mu D & 0 \\
\mu D & D & 0 \\
0 & 0 & \frac{D}{2}(1-\mu)
\end{array}\right]} \\
& D=\frac{E^{3}}{12\left(1-\mu^{2}\right)}
\end{aligned}
$$

The critical of buckling load, $\mathrm{N}_{\mathrm{cr}}$ is calculated by the following equation,

$\operatorname{Det}\left(\left[K^{*}\right]-\lambda_{b}\left[K_{g}^{*}\right]\right)=0$

$\lambda_{\mathrm{b}}=-\frac{\mathrm{N}_{\mathrm{x}}}{\mathrm{N}_{\mathrm{x}}^{\mathrm{b}}}$

$\mathrm{K}^{*}$ and $\mathrm{K}_{\mathrm{B}}^{*}$ are transformations of bending and geometric stiffmess matrices.

\section{Finite element modelling}

The finite element method have proved to be extremely powerful and versatile tools for the analysis of a wide variety of plate problems. In figure 5, the model of a symmetrical plate with a central circular hole is shown. It is consists of 69 nodes and 13 
elements. In figure 6 , the model of a symmetrical plate without hole is composed of 81 nodes and 16 elements. In the models are used the nine - node isoparanetric element.

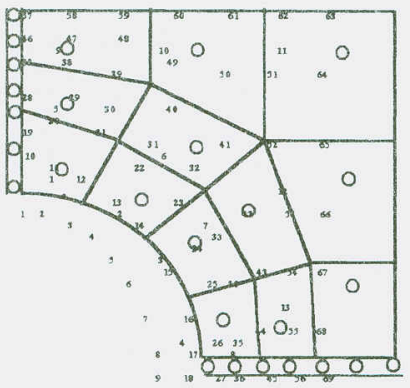

Fig.5. Modelod element mesh for orthotropic plate. with a central hole

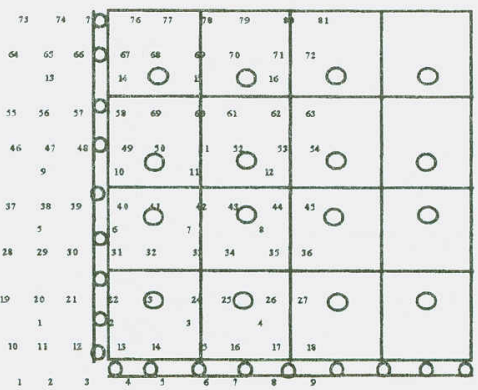

Fig.6.Modeled element mesh for orthotropic plate without hole.

\section{Computer program}

The basic theory, incorporated into the computer program used for this investigation, can be found. Computer generated results are presented in tabular forms. The computer program used is coded in FORTRAN. The program is developed using the formulation of the equation of orthotropic and isotropic plates. In this program, finite elements meshes are automatically found by subprogram MESH. Two dimensional finite element model is used. This program have nine - node plane isoparametric element. The stiffness matrix and the load vector are evaulated by subroutines presented here. There are five degrees of freedom per node in the element. The program containes only nine node quadrilateral isoparametric elements. Two examples (one is with hole another is without hole) of application of the computer program are given below.

\section{Numerical example and discussions}

The plates are assumed to be under uniform axial loads the rectangular edges of the plates and the circular hole is free.Effects of hole size on critical buckling loads of the orthotropic rectangular simple plates under uniaxial compressions are shown in Table1. Finite element meshes of the plate with and without hole are shown in figure 5 and 6 . The rectangular reinforced plate simply supported at the edges, with dimensions $3 \mathrm{~m} . \times 3 \mathrm{~m} \times 0.2 \mathrm{~m}$., was discussed. Number of laminates is 6 .

Buckling load of the plate without hole is $-144.3 \mathrm{~N} / \mathrm{mm}$. 
TABLE 1. Buckling loads of the plate according to diameters of holes.

\begin{tabular}{|c|c|}
\hline Hole diameter (mmon) & Buckling load (N/mmen \\
\hline & \\
\hline 10 & -195.3 \\
\hline 50 & -194.4 \\
\hline 100 & -193.5 \\
\hline 200 & -192.6 \\
\hline 400 & -192.6 \\
\hline 600 & -192.6 \\
\hline 800 & -191.0 \\
\hline 900 & -189.3 \\
\hline 1000 & -187.4 \\
\hline 1100 & -184.7 \\
\hline
\end{tabular}

\section{Conclusions}

The presence of hole significantly affects the buckling behaviour and optimum design of laminated plates. Finite element results were obtained for simply supported stress loaded plates loaded by uniaxial compression. Results are presented that predict the effects of hole size.

A basic characteristic of compression - loaded rectangular orthotropic plates with hole is that under certain circumtances they exhibit higher buckling loads than corresponding plates without hole.

The effect deals with the plate bending stiffness. Inherently associated with a centrally located hole is a loss in bending stiffness in the central region of a plate that grows in importance as the hole size increases. The increase in loss of bending stiffness due to increase in hole size yields a reduction in buckling resistance.

\section{References}

1.LIN,C.C., KUO, C.S., 1987.Buckling of Laminated with Holes.Journal of Composite Materials. Vol.23 - June 1989.

2.AKBULUT,H.,KARAKUZU,R,SAYMAN,O.,1995.Dikdörtgen delikli kompozit plaklarda burkulma katsayılarmın bulunması.9. Uhusal Mekanik Kongresi.

3.SAYMAN,O.,AKSOY,S.Kompozit Malzemeler.E.Ü.İMiR.

4.TURVEY,G.J.,MARSHALL,I.H., 1995.Buckling and Postbuckling of Composite Plates. ChapmanHall.LONDON.

5.SZILARD, R, 1974. Theory and Analysis of Plates.U.S.A. 